\title{
Radiographic Hip Involvement in Ankylosing Spondylitis: Factors Associated with Severe Hip Diseases
}

\author{
Jinzhu Zhao, Wei Zheng, Chao Zhang, Jia Li, Denghui Liu, and Weidong Xu
}

\begin{abstract}
Objective. To determine the factors associated with severe radiographic hip involvement in patients with ankylosing spondylitis (AS).

Methods. A cross-sectional retrospective study was performed. The patients were classified into 3 groups based on the Bath Ankylosing Spondylitis Radiology Hip Index (BASRI-hip): minimal hip disease, moderate hip disease, and severe hip disease. Demographic, clinical, radiographic, and laboratory data were collected and analyzed. To identify factors associated with severe hip disease, ordinal regression analyses were performed.

Results. A total of 256 patients were involved in the study. There were differences in the age at onset, delay in diagnosis, bilateral hip involvement, sacroiliitis, Schober's index, and occiput-to-wall distance among the 3 groups $(\mathrm{p}<0.05)$. The patients with severe hip disease had lower C-reactive protein and erythrocyte sedimentation rate levels than did the minimal group $(\mathrm{p}<0.05)$. The functional status based on the Bath Ankylosing Spondylitis Functional Index and the Harris Hip Score showed significant differences $(\mathrm{p}<0.05)$. The results of the ordinal regression analyses showed that bilateral hip involvement, sacroiliitis, delay in diagnosis, age at onset, and spinal involvement were associated with a higher BASRI-hip $(\mathrm{p}<0.05)$.

Conclusion. Bilateral hip involvement, severe sacroiliitis, longer delay in diagnosis, early disease onset, and spinal involvement are associated with severe hip disease in patients with AS. The severity of hip involvement is associated with the functional status in AS. (First Release Nov 1 2014; J Rheumatol 2015;42:106-10; doi:10.3899/jrheum.140428)
\end{abstract}

Key Indexing Terms:

ANKYLOSING SPONDYLITIS

HIP INVOLVEMENT

RADIOGRAPHIC

Ankylosing spondylitis is a chronic, progressive inflammatory disease that mainly affects the axial skeleton, such as the sacroiliac joints and spine; in some cases, extraaxial sites such as the peripheral joints, eyes, enthesis, and heart may be involved ${ }^{1,2}$. Hip involvement is common in patients with AS and may lead to a worse functional outcome $3,4,5,6$, and hip ankylosing is an important endstage feature of AS that may cause permanent disability.

The diagnosis of hip involvement in AS is typically made based on 3 criteria: radiographic changes, clinical symptoms, or magnetic resonance imaging ${ }^{7}$. Of these criteria, radiographic involvement is used most commonly ${ }^{8}$. It is defined

From the Department of Orthopedics, Changhai Hospital, Second Military Medical University, Shanghai; Department of Orthopedics, No. 401 Hospital, Jinan Military Region of PLA, Qingdao City, Shandong Province; Department of Orthopedics, Tianjin Medical University General Hospital, Tianjin, China.

Jinzhu Zhao and Wei Zheng contributed equally to this work.

J. Zhao, MD, Department of Orthopedics, No. 401 Hospital; W. Zheng, $M D ; J . L i, M D ; D$. Liu, MD; W. Xu, MD, Department of Orthopedics, Changhai Hospital, Second Military Medical University; C. Zhang, MD, Department of Orthopedics, Tianjin Medical University General Hospital. Address correspondence to Dr. W. Xu, Department of Orthopedics, Changhai Hospital, Second Military Medical University, 168 Chang-Hai Road, Shanghai 200433,PR China.E-mail: proxuwd@hotmail.com Accepted for publication September 17, 2014. based on the Bath Ankylosing Spondylitis Radiology Hip Index (BASRI-hip). The BASRI-hip system is an objective and reliable method for hip involvement in AS and is used widely in clinical studies 9 .

Several studies have examined the epidemiology and risk factors of hip involvement in $\mathrm{AS}^{3,4,6}$. These results showed that about 1 out of 3 to 4 patients with AS have hip involvement. Disease duration, enthesial disease, and juvenile onset are associated with hip involvement in AS. In some cases, the structural damage and ankylosing of the hip is unavoidable, and about 5-8\% of patients with AS undergo hip replacement surgery ${ }^{3,6}$. Some cases might achieve longterm remission of progressive hip involvement. These results indicate that the severity and progressive speed of hip involvement are different between individuals. It is helpful to identify the factors that are associated with the radiographic severity after hip involvement, and therapeutic strategies could be performed to prevent the deterioration of hip involvement.

There are few data regarding the factors that are associated with the progress of radiographic changes in hip disease in AS. The aim of our study was to investigate the factors associated with severe radiographic hip involvement in patients with AS. 


\section{MATERIALS AND METHODS}

Study subjects. A total of 256 patients with AS who were referred to our orthopedics outpatient clinics from December 2010 to December 2013 were included in a cross-sectional, retrospective study. All of the patients met the modified New York criteria for $\mathrm{AS}^{10}$ and had radiographic hip involvement according to the BASRI-hip ${ }^{9}$. Written informed consent was obtained from all the subjects, and the study was approved by the local ethics committee of Changhai Hospital (Shanghai, PR China). The subjects' characteristics are given in Table 1 .

Clinical data. The following clinical data were collected from all patients: age, sex, disease duration, initial symptoms of AS (low back pain, hip involvement, enthesitis, and others), age at disease onset, delay in diagnosis, family history of AS, treatment history [the usage of tumor necrosis factor (TNF) blockers]. Clinical examinations were performed by the same observer and included Schober's index and the occiput-to-wall distance.

Disease assessment. The Bath Ankylosing Spondylitis Functional Index $(\mathrm{BASFI})^{11}$, Harris Hip Score ${ }^{12}$, and Bath Ankylosing Spondylitis Disease Activity Index (BASDAI) ${ }^{13}$ were used to assess the functional status, hip function, and disease activity, respectively.

Radiological assessment. The BASRI-hip was used to assess radiographic hip involvement. The BASRI-hip is a reliable method for grading hip radiographic changes in $\mathrm{AS}^{9}$. It was graded as follows: $0=$ no disease (no change), 1 = suspicious disease (possible focal joint space narrowing), $2=$ minimal disease (definite narrowing, leaving a circumferential joint space

Table 1. Demographic and clinical characteristics, and laboratory and radiographic data of $256 \mathrm{AS}$ patients with radiographic hip involvement.

\begin{tabular}{lcc}
\hline Variable & Value & Range \\
\hline Age, yrs, mean (SD) & $34.00(8.26)$ & $17.10-63.00$ \\
Disease duration, yrs, mean (SD) & $11.01(5.60)$ & $3.02-39.00$ \\
Age at onset, yrs, mean (SD) & $22.99(5.50)$ & $12.00-47.00$ \\
Delay in diagnosis, yrs, mean (SD) & $3.86(2.04)$ & $0.20-10.00$ \\
Male sex, n (\%) & $226(88.28)$ & \\
Male/female, ratio & $7.53: 1$ & \\
HLA-B27+, n (\%) & $236(92.20)$ & \\
Family history, n (\%) & $28(10.94)$ & \\
TNF blockers, $\mathrm{n}(\%)$ & $50(19.5)$ & \\
Initial symptom at disease onset & & \\
Low back pain, n (\%) & $155(60.55)$ & \\
Hip joint, n (\%) & $42(11.41)$ & \\
Enthesitis, n (\%) & $27(10.55)$ & \\
Others, n (\%) & $31(12.11)$ & \\
Bilateral hip, $\mathrm{n}(\%)$ & $245(95.70)$ & \\
Schober's index, cm, mean (SD) & $2.59(0.85)$ & \\
Occiput-to-wall distance, cm, & & \\
$\quad$ mean (SD) & $15.59(6.17)$ & $5.00-43.00$ \\
Sacroiliitis score, mean (SD) & $3.22(0.65)$ & \\
BASFI, mean (SD) & $6.13(1.33)$ & $3.00-9.30$ \\
BASDAI, mean (SD) & $5.09(0.97)$ & $3.00-8.00$ \\
Harris Hip Score, mean (SD) & $45.52(12.11)$ & $17.00-83.00$ \\
CRP, mg/dl, mean (SD) & $3.16(1.01)$ & $1.10-5.80$ \\
ESR, mm/h, mean (SD) & $5.80(3.16)$ & $10.00-60.00$ \\
BASRI-hip & & \\
2, n (\%) & $107(41.80)$ & \\
3, n (\%) & $73(28.51)$ & \\
4, n (\%) & $76(29.69)$ & \\
\hline
\end{tabular}

AS: ankylosing spondylitis; TNF: tumor necrosis factors; BASFI: Bath Ankylosing Spondylitis Functional Index; BASDAI: Bath Ankylosing Spondylitis Disease Activity Index; CRP: C-reactive protein; ESR: erythrocyte sedimentation rate; BASRI-hip: Bath Ankylosing Spondylitis Radiology Hip Index.
$>2 \mathrm{~mm}$ ), $3=$ moderate disease (narrowing but with circumferential joint space $\leq 2 \mathrm{~mm}$ or bone-on-bone apposition of $<2 \mathrm{~cm}$ ), $4=$ severe disease (bone deformity or bone-on-bone apposition $>2 \mathrm{~cm}$ or total hip replacement). Radiographic hip involvement was defined as a BASRI-hip score of at least grade 2. Bilateral hip involvement was defined as BASRI-hip scores of both hips $\geq 2$. Anteroposterior pelvic radiographs were scored separately by 2 trained independent readers. When there was disagreement between the 2 readers, a senior physician made the final decision. The patients were classified into 3 categories based on their BASRI-hip scores: minimal hip disease (score of 2), moderate hip disease (score of 3), and severe hip disease (score of 4). Sacroiliitis was graded on the anteroposterior pelvic radiograph, according to the New York scale ${ }^{10}$. Imaging studies were performed on the same day as the patient reported outcomes and inflammatory markers.

Laboratory measurements. The HLA-B27 status, erythrocyte sedimentation rate (ESR), and C-reactive protein (CRP) were evaluated and recorded in all subjects.

Statistical analysis. The subjects' characteristics were described as the means (SD) for quantitative data and as proportions for qualitative data. To compare differences of continuous data, we used a 1-way ANOVA test. If there was a violation of variance homogeneity, Kruskal-Wallis 1-way ANOVA-rank was used. Categorical data were compared with Pearson chi-square analyses. To identify factors that are associated with severe hip disease, ordinal regression analyses were performed. The statistical analyses were conducted using SPSS 21.0 . $\mathrm{P} \leq 0.05$ was considered statistically significant.

\section{RESULTS}

Description of study subjects' characteristics. The demographics, clinical characteristics, laboratory, and radiographic data of 256 patients with AS with radiographic hip involvement are shown in Table 1. Based on the BASRI-hip, 107 patients $(41.80 \%)$ had minimal hip disease (BASRI-hip = 2), $73(28.51 \%)$ had moderate hip disease (BASRI-hip = 3), and 76 (29.69\%) had severe hip disease (BASRI-hip = 4). The average age of the patients with AS was 34.00 years (8.26). The mean disease duration was 11.01 years $(5.60)$. The age at onset was 22.99 years (5.50). The delay in diagnosis was 3.86 years (2.04). Of the 256 patients, 226 $(88.28 \%)$ were male, and the ratio of males to females was 7.53:1. A total of 245 patients $(95.70 \%)$ had bilateral hip involvement, $28(10.94 \%)$ had a family history of AS, 50 $(19.5 \%)$ had been treated with tumor necrosis factor (TNF) blockers, and 236 (92.20\%) were HLA-B27-positive.

Regarding the initial symptoms at disease onset, low back pain was the most common $(60.55 \%)$, followed by hip joint $(11.41 \%)$, and enthesitis $(12.11 \%)$; other symptoms, such as uveitis and inflammatory bowel disease, accounted for $10.55 \%$ of initial symptoms. The mean Schober's index was $2.59 \mathrm{~cm}(0.85)$, and the occiput-to-wall distance was $15.59 \mathrm{~cm}$ (6.17). The mean BASDAI score, BASFI score, Harris Hip Score, and sacroiliitis index were 5.09 (0.97), $6.13(1.33), 45.52(12.11)$, and $3.22(0.65)$, respectively. The laboratory test levels for ESR and CRP were $5.80 \mathrm{~mm} / \mathrm{h}$ (3.16) and $3.16 \mathrm{mg} / \mathrm{dl}$ (1.01), respectively.

Comparison of patient characteristics among 3 subgroups. Table 2 shows the differences in patient characteristics among the 3 groups of hip-involved patients with AS. ANOVA analyses were used to compare differences in mean

Personal non-commercial use only. The Journal of Rheumatology Copyright $\subset$ C 2015. All rights reserved. 
age, age at onset, delay in diagnosis, Schober's index, BASDAI, BASFI, CRP, and ESR among the 3 groups. If there was a violation of variance homogeneity, Kruskal-Wallis 1-way ANOVA-rank was used to compare differences in disease duration, occiput-to-wall distance, and Harris Hip Score. The results showed that there were differences in the age, age at onset, and delay in diagnosis among the 3 subgroups $(\mathrm{p}=0.004, \mathrm{p}=0.001$, and $\mathrm{p}=$ $0.001)$. Disease activity status measured by the BASDAI, the functional measures based on the BASFI score, and the Harris Hip Score showed significant differences $(p=0.048$, $\mathrm{p}=0.001$, and $\mathrm{p}<0.001$, respectively). Schober's index and the occiput-to-wall distance were significantly different among the 3 groups. Patients with more severe hip disease had lower CRP and ESR levels than the minimal group. Sacroiliitis score was significantly different among the 3 groups $(\mathrm{p}<0.001)$. No differences were found in disease duration $(\mathrm{p}=0.464)$.

Pearson chi-square analyses were used to measure difference in sex, HLA-B27 positivity, family history, initial symptom at onset, treatment history, and bilateral hip involvement among groups. No differences were found in sex distribution, family history of AS, initial symptom at onset, use of TNF blockers, and percentage of HLA-B27 carriers. Bilateral hip involvement was significantly different among groups $(p=0.005)$.
Factors associated with higher BASRI-hip score. Separate regression analyses were performed to determine baseline risk factors for severe hip disease. OR (95\% CI) were calculated. For the initial selection of multivariate risk factors, univariate risk factors with a $\mathrm{p}$ value $<0.20$ were chosen Finally, bilateral hip involvement, sacroiliitis, occiput-to-wall distance, delay in diagnosis, age at onset, and Schober's index were included in the regression model (Table 3). Multivariate ordinal regression analyses were performed.

The results showed that bilateral hip involvement was the most significant factor associated with severe hip disease (OR 14.25, 95\% CI 2.56-73.44, $\mathrm{p}=0.002$ ). It was followed by sacroiliitis (OR 4.93, 95\% CI 3.12-7.79, p < 0.001), occiput-to-wall distance (OR 3.04, 95\% CI 1.95-4.75, p < 0.001 ), delay in diagnosis (OR 2.35, 95\% CI 1.36-4.08, $\mathrm{p}=$ 0.002 ), age at onset (OR $0.46,95 \%$ CI $0.29-0.72, \mathrm{p}=$ 0.001 ), and Schober's index (OR 0.14, 95\% CI 0.05-0.40, $\mathrm{p}<0.001)$.

\section{DISCUSSION}

Our study confirmed that the severity of hip involvement is associated with a more impaired functional status (BASFI and Harris Hip Score) in AS and more limited spinal mobility measured by the occiput-to-wall distance and Schober's index. We determined that the severity of radiographic hip disease in AS is associated with age at

Table 2. Comparison of clinical, laboratory, and radiographic data between 3 groups based on BASRI-hip scores in hip-involved patients with ankylosing spondylitis.

\begin{tabular}{|c|c|c|c|c|}
\hline No. Patients & 107 & 73 & 76 & \\
\hline Age at onset, yrs, mean (SD) & $24.33(5.22)$ & $22.77(4.93)$ & $21.32(5.97)$ & 0.001 \\
\hline Disease duration, yrs, mean (SD) & $11.66(6.28)$ & $9.90(5.33)$ & $11.16(4.68)$ & 0.464 \\
\hline Delay in diagnosis, yrs, mean (SD) & $3.46(2.00)$ & $3.68(2.04)$ & $4.59(1.91)$ & 0.001 \\
\hline Family history, n (\%) & $14(13.08)$ & $8(10.96)$ & $6(7.89)$ & 0.541 \\
\hline TNF blockers, $\mathrm{n}(\%)$ & $21(19.6)$ & $18(24.7)$ & $11(14.5)$ & 0.293 \\
\hline Initial symptom at disease onset & & & & 0.861 \\
\hline Low back pain, $\mathrm{n}(\%)$ & $70(65.42)$ & $43(58.90)$ & $42(55.26)$ & \\
\hline Hip joint, $\mathrm{n}(\%)$ & $14(13.08)$ & $13(17.81)$ & $15(19.74)$ & \\
\hline Enthesitis, n (\%) & $12(11.22)$ & $10(13.70)$ & $10(13.16)$ & \\
\hline Occiput-to-wall distance, $\mathrm{cm}$, mean (SD) & $13.69(4.73)$ & $14.41(4.35)$ & $19.38(7.66)$ & $<0.001$ \\
\hline BASFI, mean (SD) & $5.81(1.25)$ & $6.15(1.30)$ & $6.55(1.36)$ & 0.001 \\
\hline BASDAI, mean (SD) & $4.91(0.91)$ & $5.23(0.93)$ & $5.17(1.02)$ & 0.048 \\
\hline Harris Hip Score, mean (SD) & $53.41(11.09)$ & $44.73(8.09)$ & $35.18(8.00)$ & $<0.001$ \\
\hline $\mathrm{CRP}, \mathrm{mg} / \mathrm{dl}$, mean $(\mathrm{SD})$ & $3.33(1.09)$ & $3.13(0.89)$ & $2.94(0.95)$ & 0.036 \\
\hline $\mathrm{ESR}, \mathrm{mm} / \mathrm{h}$, mean $(\mathrm{SD})$ & $35.93(9.94)$ & $31.40(9.29)$ & $28.03(10.61)$ & $<0.001$ \\
\hline
\end{tabular}

TNF: tumor necrosis factors; BASFI: Bath Ankylosing Spondylitis Functional Index; BASDAI: Bath Ankylosing Spondylitis Disease Activity Index; CRP: C-reactive protein; ESR: erythrocyte sedimentation rate; BASRI-hip: Bath Ankylosing Spondylitis Radiology Hip Index. 
Table 3. Factors associated with higher BASRI-hip.

\begin{tabular}{lcc}
\hline Factors & OR $(95 \%$ CI $)$ & $\mathrm{p}$ \\
\hline Bilateral hip involvement & $14.25(2.56,73.44)$ & 0.002 \\
Sacroiliitis score & $4.93(3.12,7.79)$ & $<0.001$ \\
Occiput-to-wall distance, per $10 \mathrm{~cm}$ & $3.04(1.95,4.75)$ & $<0.001$ \\
Delay in diagnosis $>5$ yrs & $2.35(1.36,4.08)$ & 0.002 \\
Age at onset, per 10 yrs & $0.46(0.29,0.72)$ & 0.001 \\
Schober's index $\geq 4 \mathrm{~cm}$ & $0.14(0.05,0.40)$ & $<0.001$ \\
\hline
\end{tabular}

BASRI-hip: Bath Ankylosing Spondylitis Radiology Hip Index.

onset, delay in diagnosis, bilateral involvement, and severe sacroiliitis. Disease duration, sex, HLA-B27, family history, and BASDAI showed no association with severity of hip disease. Inflammatory biomarkers, such as ESR and CRP, were higher in minimal hip disease. Based on ordinal regression analyses, we defined the factors associated with severe hip involvement in AS, which included bilateral hip involvement, severe sacroiliitis, spinal involvement, longer delay in diagnosis, and early onset.

We found a strong correlation between severity of radiographic hip damage and BASFI scores in patients with $\mathrm{AS}$, and more severe radiographic hip involvement contributed to higher BASFI scores. The same result was found in terms of the Harris Hip Score. The hip joint plays an important role in bipedalism and movement function in human beings. Previous reports have shown that patients with clinical or radiological hip involvement have worse BASFI scores than those without hip involvement, and this could lead to impaired physical functioning $3,4,5,6$. In our study, the severity of hip involvement was associated with limitations of spinal mobility, such as low Schober's index and occiput-to-wall distance, indicating that hip involvement patients have more severe axial damage, making them susceptible to a decline in physical function. These results are consistent with previous studies ${ }^{4}$. For the individuals with more severely involved hips and those with worse functional status, total hip arthroplasty was considered ${ }^{3,14,15}$. This demonstrates the necessity of preventing the deterioration of hip involvement and taking early measures to allow these patients to have a better functional status.

Some reports indicate that patients with juvenile onset have more hip involvement, and this is associated with total hip arthroplasty in $\mathrm{AS}^{3,16,17,18}$. In our study, we determined that younger age at onset is closely related to severe hip disease in AS. The age at onset (per $10 \mathrm{yrs}$ ) is a protective factor of developing more severe radiographic hip disease (OR $0.46,95 \%$ CI $0.29-0.72, \mathrm{p}=0.001$ ).

Disease duration has been shown to be associated with hip involvement ${ }^{3,4}$, but we found no association between disease duration and more severe hip disease in AS. In our study, patients with AS who had more severe hip disease involvement had a longer duration of diagnosis delay but did not have longer disease duration. A delay in diagnosis indicates misdiagnosis and inappropriate treatment in early stages. This result indicates that it is important to make the diagnosis early and implement the appropriate therapeutic strategy for reducing the occurrence and development of severe hip involvement in hip-involved patients with AS.

The susceptibility of AS has a strong association with young males and the HLA-B27 genotype ${ }^{1,2}$. In our study, the presence of HLA-B27, a family history of AS, and sex distribution were not different among patients with different severities of hip involvement. These results were consistent with the study by Burki, et $a l^{6}$. That study showed that genetic factors might play a minor role in the processing of hip disease in hip-involved patients with AS. Regarding initial symptoms, inflammatory back pain was the most commonly affected site, followed by enthesitis and the hip joints. There was no difference in initial symptoms among the subgroups.

TNF blockers are effective in relieving symptoms and improving disease status ${ }^{19,20,21}$. However, it is unclear whether TNF blockers could prevent structural damage in AS. Some studies reported that TNF inhibitors fail to substantially slow new bone formation in $\mathrm{AS}^{22,23,24}$; some studies show it appears to be associated with increased structural damage ${ }^{25}$ and some studies showed a potential benefit of TNF blockers on radiographic progression in $\mathrm{AS}^{26,27,28,29,30,31}$. In some studies ${ }^{26}$, the effect of longterm treatment with the TNF blocker infliximab (IFX) on radiographic progression of hip arthritis in AS was studied, and the authors found that radiographic progression of hip arthritis in AS may be arrested during IFX treatment. We reviewed the clinical data on use of TNF blockers in our study and found no significant difference among the 3 groups $(\mathrm{p}=0.293)$.

The levels of laboratory inflammatory biomarkers, such as CRP and ESR, were different among the 3 groups in our study. Minimal hip disease is associated with a higher level of CRP and ESR; these elevations did not occur in the more severely affected groups. This result confirmed that the main pathological features of AS are different in different disease stages; inflammation lesions are predominant in the early stage, and tissue repair or ossification are predominant in advanced stages ${ }^{2}$. This finding indicates that appropriate indicators should be used in certain stages of disease in AS for evaluating the severity of the disease.

There are limitations to our study. It is a retrospective cross-sectional study, and a prospective cohort study should be performed to confirm the risk factors for severe hip disease in AS. The subjects in our study, who were patients referred to an outpatient orthopedic clinic, might represent a severely affected group. All study subjects agreed to participate, and there might be selection bias.

More severe hip involvement is associated with a worse functional status in AS. Bilateral hip involvement, severe sacroiliitis, longer delay in diagnosis, early disease onset,

Personal non-commercial use only. The Journal of Rheumatology Copyright @ 2015 . All rights reserved. 
and spinal involvement are associated with severe hip disease in patients with AS. Disease duration, sex, HLA-B27, and family history showed no association with the severity of hip disease. Inflammatory biomarkers, such as ESR and CRP, cannot reflect disease severity in advanced stages. To improve the quality of life of hip-involved patients with AS, the diagnosis and treatment of hip disease should be done in the early stage, especially in patients with AS diagnosed at an early age, those who have bilateral hip involvement, and patients with severe sacroiliitis.

\section{ACKNOWLEDGMENT}

The authors thank the patients who were involved in this study.

\section{REFERENCES}

1. Braun J, Sieper J. Ankylosing spondylitis. Lancet 2007; 369:1379-90.

2. Dougados M, Baeten D. Spondyloarthritis. Lancet 2011; 377:2127-37.

3. Vander CB, Munoz-Gomariz E, Font P, Mulero J, de Vlam K, Boonen A, et al. Hip involvement in ankylosing spondylitis: epidemiology and risk factors associated with hip replacement surgery. Rheumatology 2010;49:73-81.

4. Chen HA, Chen CH, Liao HT, Lin YJ, Chen PC, Chen WS, et al. Factors associated with radiographic spinal involvement and hip involvement in ankylosing spondylitis. Semin Arthritis Rheum 2011;40:552-8

5. Cansu DU, Calışır C, Savaş Yavaş U, Kaşifoğlu T, Korkmaz C. Predictors of radiographic severity and functional disability in Turkish patients with ankylosing spondylitis. Clin Rheumatol 2011;30:557-62.

6. Burki V, Gossec L, Payet J, Durnez A, Elhai M, Fabreguet I, et al. Prevalence and characteristics of hip involvement in spondyloarthritis: a single-centre observational study of 275 patients. Clin Exp Rheumatol 2012;30:481-6.

7. Vander CB, Vastesaeger N, Collantes-Estevez E. Hip disease in ankylosing spondylitis. Curr Opin Rheumatol 2013;25:448-54.

8. Boutry N, Khalil C, Jaspart M, Marie-Hélène V, Demondion X, Cotten A. Imaging of the hip in patients with rheumatic disorders. Eur J Radiol 2007;63:49-58.

9. Mackay K, Brophy S, Mack C, Doran M, Calin A. The development and validation of a radiographic grading system for the hip in ankylosing spondylitis: the Bath Ankylosing Spondylitis Radiology Hip Index. J Rheumatol 2000;27:2866-72.

10. Van der Linden S, Valkenburg HA, Cats A. Evaluation of diagnostic criteria for ankylosing spondylitis. A proposal for modification of the New York criteria. Arthritis Rheum 1984;27:361-8.

11. Calin A, Garrett S, Whitelock H, Kennedy LG, O'Hea J, Mallorie P, et al. A new approach to defining functional ability in ankylosing spondylitis: the development of the Bath Ankylosing Spondylitis Functional Index. J Rheumatol 1994;21:2281-5.

12. Nilsdotter A, Bremander A. Measures of hip function and symptoms: Harris Hip Score (HHS), Hip Disability and Osteoarthritis Outcome Score (HOOS), Oxford Hip Score (OHS), Lequesne Index of Severity for Osteoarthritis of the Hip (LISOH), and American Academy of Orthopedic Surgeons (AAOS) Hip and Knee Questionnaire. Arthritis Care Res 2011;63 Suppl 11:200-7.

13. Garrett S, Jenkinson T, Kennedy LG, Whitelock H, Gaisford P, Calin A. A new approach to defining disease status in ankylosing spondylitis: the Bath Ankylosing Spondylitis Disease Activity Index. J Rheumatol 1994;21:2286-91.

14. Sweeney S, Gupta R, Taylor G, Calin A. Total hip arthroplasty in ankylosing spondylitis: outcome in 340 patients. J Rheumatol
2001;28:1862-6.

15. Joshi AB, Markovic L, Hardinge K, Murphy JC. Total hip arthroplasty in ankylosing spondylitis: an analysis of 181 hips. J Arthroplasty 2002;17:427-33.

16. Calin A, Elswood J. The relationship between pelvic, spinal and hip involvement in ankylosing spondylitis - one disease process or several? Br J Rheumatol 1988;27:393-5.

17. Brophy S, Calin A. Ankylosing spondylitis: interaction between genes, joints, age at onset, and disease expression. J Rheumatol 2001;28:2283-8

18. Gensler LS, Ward MM, Reveille JD, Learch TJ, Weisman MH, Davis JC Jr. Clinical, radiographic and functional differences between juvenile-onset and adult-onset ankylosing spondylitis: results from the PSOAS cohort. Ann Rheum Dis 2008;67:233-7.

19. Braun J, Pavelka K, Ramos-Remus C, Dimic A, Vlahos B, Freundlich B, et al. Clinical efficacy of etanercept versus sulfasalazine in ankylosing spondylitis subjects with peripheral joint involvement. J Rheumatol 2012;39:836-40.

20. Inman RD, Maksymowych WP. A double-blind, placebo-controlled trial of low dose infliximab in ankylosing spondylitis. J Rheumatol 2010;37:1203-10.

21. Rudwaleit M, Claudepierre P, Wordsworth P, Cortina EL, Sieper J, Kron M, et al. Effectiveness, safety, and predictors of good clinical response in 1250 patients treated with adalimumab for active ankylosing spondylitis. J Rheumatol 2009;36:801-8.

22. Van der Heijde D, Landewe R, Einstein S, Ory P, Vosse D, Ni L, et al. Radiographic progression of ankylosing spondylitis after up to two years of treatment with etanercept. Arthritis Rheum 2008;58:1324-31.

23. Van der Heijde D, Landewe R, Baraliakos X, Houben H, van Tubergen A, Williamson P, et al. Radiographic findings following two years of infliximab therapy in patients with ankylosing spondylitis. Arthritis Rheum 2008;58:3063-70.

24. Van der Heijde D, Salonen D, Weissman BN, Landewe R, Maksymowych WP, Kupper H, et al. Assessment of radiographic progression in the spines of patients with ankylosing spondylitis treated with adalimumab for up to 2 years. Arthritis Res Ther 2009;11:R127.

25. Kang KY, Ju JH, Park SH, Kim HY. The paradoxical effects of TNF inhibitors on bone mineral density and radiographic progression in patients with ankylosing spondylitis. Rheumatology 2013;52:718-26.

26. Konsta M, Sfikakis PP, Bournia VK, Karras D, Iliopoulos A Absence of radiographic progression of hip arthritis during infliximab treatment for ankylosing spondylitis. Clin Rheumatol 2013;32:1229-32.

27. Dijkmans B, Emery P, Hakala M, Leirisalo-Repo M, Mola EM, Paolozzi L, et al. Etanercept in the longterm treatment of patients with ankylosing spondylitis. J Rheumatol 2009;36:1256-64.

28. Baraliakos X, Haibel H, Listing J, Sieper J, Braun J. Continuous long-term anti-TNF therapy does not lead to an increase in the rate of new bone formation over 8 years in patients with ankylosing spondylitis. Ann Rheum Dis 2014;73:710-5.

29. Haroon N, Inman RD, Learch TJ, Weisman MH, Lee M, Rahbar $\mathrm{MH}$, et al. The impact of tumor necrosis factor alpha inhibitors on radiographic progression in ankylosing spondylitis. Arthritis Rheum 2013;65:2645-54.

30. Baraliakos X, Listing J, Brandt J, Haibel H, Rudwaleit M, Sieper J, et al. Radiographic progression in patients with ankylosing spondylitis after 4 yrs of treatment with the anti-TNF-alpha antibody infliximab. Rheumatology 2007;46:1450-3.

31. Baraliakos X, Listing J, Rudwaleit M, Brandt J, Sieper J, Braun J. Radiographic progression in patients with ankylosing spondylitis after 2 years of treatment with the tumour necrosis factor alpha antibody infliximab. Ann Rheum Dis 2005;64:1462-6. 